\title{
Teething symptoms: cross sectional survey of five groups of child health professionals
}

\author{
Melissa Wake, Kylie Hesketh
}

Centre for Community Child Health, Roval Children's Hospital, Flemington Road, Parkville Victoria 3052, Australia Melissa Wake director, research and public health Kylie Hesketh research assistant Correspondence to: Dr Wake

wakem@cryptic. rch.unimelb.edu.au

BMJ 2002;325:814
"There can be no excuse for ascribing fever, fits, diarrhoea, bronchitis, or rashes to teething," wrote the $B M J$ in $1975 .{ }^{1}$ The intervening quarter century has seen the growth of evidence based medicine, yet it has also illustrated how great may be the distance between research evidence and professional practice and how slowly that gap may close.

Good evidence now exists from careful prospective studies that teething is associated with, at most, minor and relatively infrequent symptoms. ${ }^{2-3}$ How do the views of professionals now align with the evidence? This study aimed to determine current beliefs about teething and related practices of child health professionals in Victoria, Australia.

\section{Methods and results}

We surveyed representative samples of the five groups of professionals most closely concerned with the health of children in Victoria (population 4.6 million). A written questionnaire was mailed in July 1997 to 100 maternal and child health nurses, 100 pharmacists, 150 general practitioners, 100 dentists, and 100 paediatricians. All samples were selected randomly from state registers held by the relevant professional bodies. A parent survey on teething was conducted simultaneously, ${ }^{4}$ with many questions shared across the two surveys. SPSS version 6.1 was used for all analyses. The study was approved by the Royal Children's Hospital ethics in human research committee.

The overall response rate was $85 \%$ (73 pharmacists, $114(76 \%)$ general practitioners, 88 paediatricians, 91 dentists, and 98 nurses). Analysis of variance showed professional group, but not sex or years since graduation, to be a significant indicator of total number of symptoms ascribed to teething. The mean number of different symptoms ascribed to teething per group was 2.8 (paediatricians), 4.4 (dentists), 6.5 (general practitioners), 8.4 (pharmacists), and 9.8 (nurses). In every professional group most thought that at least some infants or young children suffer symptoms, though beliefs about the prevalence of teething symptoms varied strikingly by professional group (figure).

Thirty two pharmacists and 19 dentists reported that teething may cause fever $\left(>38^{\circ} \mathrm{C}\right)$, compared with seven nurses, 12 general practitioners, and two paediatricians. Only nine paediatricians, but $30-50 \%$ of each of the other groups, believed that teething predisposes to infections, most commonly colds and ear infections. In every group most of those who believed that teething causes symptoms ascribed irritability, dribbling or drooling, biting objects, sleep problems, inflamed gums, and red cheeks to teething. Very few from any group ascribed eczema, other rashes, colic, convulsions, or constipation to teething. Only nurses commonly ascribed nappy rash, feeding problems, pulling ears, loose stools, cold symptoms, and smelly urine to teething.

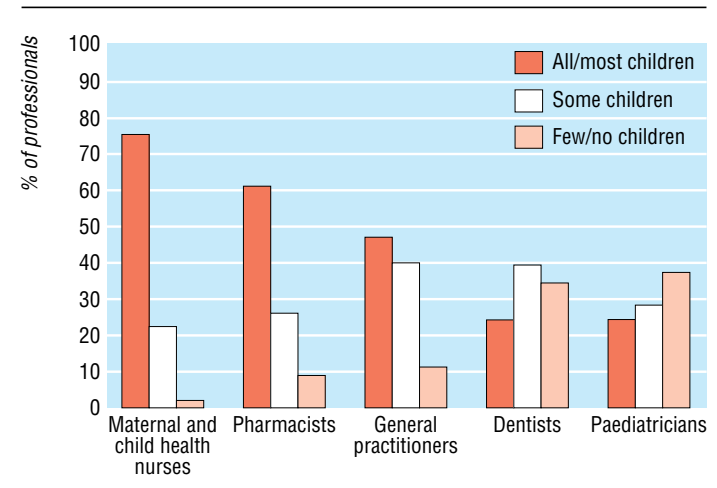

Percentage of each professional group reporting whether all or most, some, or few or no children have teething symptoms

Professionals in all groups believed that parents experience as much (or more) distress as the infants themselves (mean perceived distress rating $2.0 v 1.6 \mathrm{on}$ a 3 point scale, $\mathrm{p}<0.001$; independent samples $t$ test).

Paracetamol and teething gels were widely recommended by all groups, and 41 pharmacists recommended sedating medication. Few from any group recommended antibiotics or naturopathic medications.

\section{Comment}

Australian child healthcare professionals report strong beliefs that teething causes a range of symptoms. These beliefs are strikingly similar to those reported by Australian parents ${ }^{4}$ and by paediatricians in different places and at different times. ${ }^{5}$ Our representative samples and high response rates give us confidence in our findings.

These beliefs may prevent professionals from effectively managing some of the common developmental issues of infancy and might lead to late diagnosis of important illness. Furthermore, professionals widely recommend medication for "teething." Will these beliefs alter, now that we know how innocuous teething is? ${ }^{2}$

We thank Dr James Lucas, deputy director of dentistry at the Royal Children's Hospital, for his input to development of the questionnaire.

Contributors: The research plan was formulated by MW and implemented by KH. Data management and analysis were implemented by KH under supervision of MW. Both authors drafted the paper. MW will act as guarantor for the paper. Funding: Royal Children's Hospital Research Foundation. Competing interests: None.

1 Teething myths. BMJ 1975;iv:604.

2 Wake M, Hesketh K, Lucas J. Teething and tooth eruption in infants: a cohort study. Pediatrics 2000;106:1374-9.

3 Macknin ML, Piedmonte M, Jacobs J, Skibinski C. Symptoms associated with infant teething: a prospective study. Pediatrics 2000;105:747-52.

4 Wake M, Hesketh K, Allen M. Parent beliefs about infant teething: a survey of Australian parents. J Paediatr Child Health 1999;35:446-9.

5 Coreil J, Price L, Barkey N. Recognition and management of teething diarrhea among Florida pediatricians. Clin Pediatr 1995;34:591-6. (Accepted 17 April 2002) 